\title{
Diversity, abundance, and distribution of NO-forming nitrite reductase-encoding genes in deep-sea subsurface sediments of the South China Sea
}

\author{
M. LI ${ }^{1, *} \mathrm{Y} . \mathrm{HONG},{ }^{2} \mathrm{H} . \mathrm{CAO}^{1}$ M. G. KLOTZ ${ }^{3}$ AND J.- D. GU ${ }^{1,4}$ \\ ${ }^{1}$ Laboratory of Environmental Microbiology and Toxicology, School of Biological Sciences, The University of Hong Kong, \\ Hong Kong SAR, China \\ ${ }^{2}$ State Key Laboratory of Tropical Oceanography (LTO), South China Sea Institute of Oceanology, Chinese Academy of \\ Sciences, Guangzhou, China \\ ${ }^{3}$ Department of Biology, University of North Carolina at Charlotte, Charlotte, NC, USA \\ ${ }^{4}$ The Swire Institute of Marine Science, The University of Hong Kong, Hong Kong SAR, China
}

\begin{abstract}
In marine ecosystems, both nitrite-reducing bacteria and anaerobic ammonium-oxidizing (anammox) bacteria, containing different types of NO-forming nitrite reductase-encoding genes, contribute to the nitrogen cycle. The objectives of study were to reveal the diversity, abundance, and distribution of NOforming nitrite reductase-encoding genes in deep-sea subsurface environments. Results showed that higher diversity and abundance of nirS gene than nirK and Scalindua-nirS genes were evident in the sediments of the South China Sea (SCS), indicating bacteria containing nirS gene dominated the NO-forming nitritereducing microbial community in this ecosystem. Similar diversity and abundance distribution patterns of both nirS and Scalindua-nirS genes were detected in this study sites, but different from nirK gene. Further statistical analyses also showed both nirS and Scalindua-nirS genes respond similarly to environmental factors, but differed from nirk gene. These results suggest that bacteria containing nirS and Scalindua-nirS genes share similar niche in deep-sea subsurface sediments of the SCS, but differed from those containing nirk gene, indicating that community structures of nitrite-reducing bacteria are segregated by the functional modules (NirS vs. NirK) rather than the competing processes (anammox vs. classical denitrification).
\end{abstract}

Received 22 February 2012; accepted 8 October 2012

Corresponding author: J.-D. Gu. Tel.: +1 8522299 0605; fax: +1 852 2559 9114; e-mail: jdgu@hkucc.hku.hk

*Present Address: Department of Earth and Environmental Sciences, University of Michigan, Ann Arbor, MI, 48109, USA

\section{INTRODUCTION}

Dissimilatory nitrate reduction to dinitrogen, the major microbial nitrogen removal processes in marine ecosystems, occurs in two major pathways under anoxic conditions, classical denitrification and anaerobic ammonium oxidation (anammox) (Klotz \& Stein 2010). In the former process, nitrite reduction to nitric oxide is the rate-limiting step that is catalyzed by either copper-containing NirK or cytochrome $c d$-1 NirS nitrite reductases (Zumft 1997). The corresponding genes encoding the catalytic subunits (nirK and nirS) have been used extensively as biomarkers to elucidate community structures of nitrite reducers in marine, estuarine, and groundwater environments, and these studies were often amended with probing for genes encoding nitric oxide (i.e., nor $B, \operatorname{nor} Z$ ) and/or nitrous oxide (nos $Z$, $n o s W$ ) reductases to identify the classical denitrifying community (Braker et al., 1998, 2001; Santoro et al., 2006; Oakley et al., 2007; Smith et al., 2007; Tamegai et al., 2007; Cao et al., 2008). For a long time, classical denitrification has been considered the only pathway for nitrogen removal from marine ecosystems before discovery of anammox as another competing process (Strous et al., 1999; Schmidt et al., 2003; Francis et al., 2007). Putative nirs genes have been identified in the genomes of anammox bacteria (Strous et al., 2006). Due to the significant 
differences in the protein sequences of nitrite reductases in classical denitrifiers and anammox bacteria, Lam et al., (2009) proposed Scalindua-nirS as a candidate biomarker for the detection of anammox bacteria of the Scalindua genus in marine environments. Li et al., (2011) further confirmed the nirS as a useful biomarker for detection of anammox bacteria in marine sediments.

Because the oxidant for ammonium oxidation in the anammox process is nitrite-derived nitric oxide (Jetten et al., 2009), both anammox and denitrification pathways compete for available nitrite (Kartal et al., 2007). Furthermore, in addition to nirK, nirS, and Scalindua-nirS geneencoded NO-forming enzymes in the nitrite-reducing denitrifiers and anammox bacteria, nitrite is also a substrate to respiratory and assimilatory ammonia-forming nitrite reductases active in ammonification, indicating another competition for substrate by a wide variety of nitrite-reducing micro-organisms. Because ammonification does not remove nitrogen from the marine ecosystem, an investigation of abundance and distribution of nirK, nirS, and Scalinduanir $S$ genes may reveal the interactions of different nitrogen removal microbial populations and the environmental conditions anammox bacteria can successfully compete nirK and nirS type denitrifiers for the available nitrite. Here, we report the molecular diversity, abundance, and distribution of nirK, nirS, and Scalindua-nirS genes in subsurface sediments of the South China Sea, the largest marginal sea in southeast Asia.

\section{MATERIALS AND METHODS}

\section{Sampling and site description}

Deep-ocean subsurface sediment samples were collected at different depths from four sites $(401,407,525$, and CF5) of the Northern quadrant of the South China Sea during the South China Sea Open Cruise by R/V Shiyan 3 in 2008. A detailed description of sampling sites and their physiochemical characteristics is provided in Fig. 1 and in our previous research (Hong et al., 2011). The geographical locations and physiochemical characteristics of the four sampling sites represented some niche differences for anammox bacteria (Hong et al., 2011) and ammonia oxidizers (Cao et al., 2012).

\section{DNA extraction and PCR amplification}

Genomic DNA was extracted from all sediment samples (collected in triplicate) using the SoilMaster DNA Extraction kit following the manufacturer's instructions (Epicentre Biotechnologies, Madison, WI, USA). PCR amplifications were performed in $50-\mu \mathrm{L}$-volume assays containing $10 \mu \mathrm{L}$ of $5 \times$ PCR GoTaq Flexi buffer (Promega, Madison, WI, USA), $3 \mu \mathrm{L}$ of $\mathrm{MgCl}_{2}$ buffer (25 mm, Promega), $1 \mu \mathrm{L}$ bovine serum albumin (100 $\mathrm{mg} \mathrm{mL}^{-1}$, Roche, Hong Kong), $1 \mu \mathrm{L}$ dNTPs ( $10 \mathrm{~mm}$, Invitrogen, Carlsbad, CA, USA), $0.3 \mu \mathrm{L}$ of GoTaq Flexi polymerase $\left(5 \mathrm{U}_{\mu} \mathrm{L}^{-1}\right.$, Pro-
Fig. 1 Descriptions of four sampling sites at deep-sea subseafloor of the South China Sea in this study.

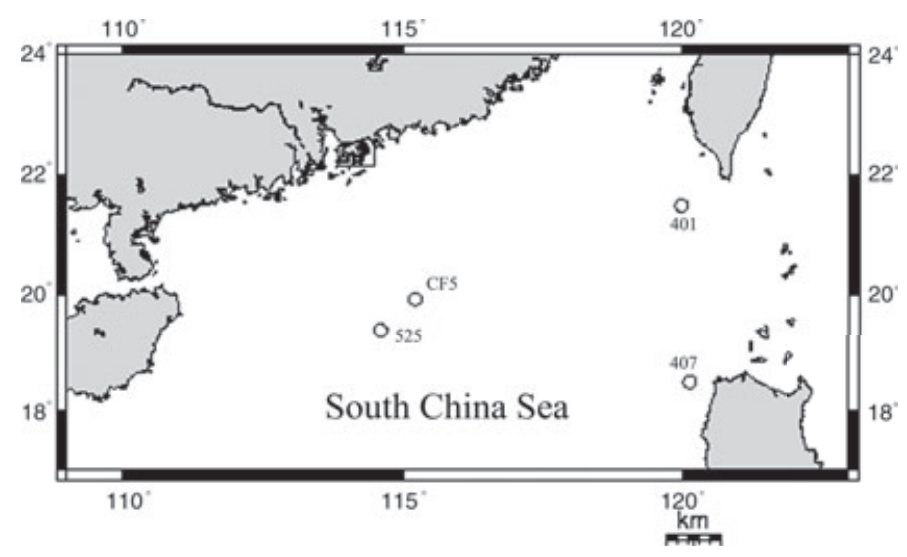

\begin{tabular}{lllll}
\hline & \multicolumn{1}{c}{$\mathbf{4 0 1}$} & $\mathbf{4 0 7}$ & $\mathbf{5 2 5}$ & CF5 \\
\hline Sampling Position & $21^{\circ} 31 \mathrm{~N} / 119^{\circ} 59 \mathrm{E}$ & $18^{\circ} 30 \mathrm{~N} / 120^{\circ} 08 \mathrm{E}$ & $19^{\circ} 23 \mathrm{~N} / 114^{\circ} 36 \mathrm{E}$ & $19^{\circ} 55 \mathrm{~N} / 115^{\circ} 13 \mathrm{E}$ \\
Depth of sea water $(\mathrm{m})$ & 3300 & 1900 & 1100 & 1153 \\
depth (mbsf) & 3.7 & 1.0 & 4.0 & 7.5 \\
Temperature $\left({ }^{\circ} \mathrm{C}\right)$ & $2 \sim 4$ & $2 \sim 4$ & $2 \sim 4$ & $2 \sim 4$ \\
$\mathrm{NH}_{4}{ }^{+}(\mathrm{mg} / \mathrm{kg})$ & $88.6 \pm 11.7$ & $13.8 \pm 0.63$ & $33.5 \pm 4.0$ & $29.9 \pm 7.5$ \\
$\mathrm{NO}_{3}^{-}(\mathrm{mg} / \mathrm{kg})$ & $234.9 \pm 17.6$ & $<0.1$ & $<0.1$ & $<0.1$ \\
$\mathrm{NO}_{2}^{-}(\mathrm{mg} / \mathrm{kg})$ & $119.8 \pm 10.8$ & $110.0 \pm 2.2$ & $114.5 \pm 1.3$ & $94.2 \pm 4.5$ \\
\hline
\end{tabular}

mbsf, meters below the sea floor (Hong et al., 2011). 
mega), $1 \mu \mathrm{L}$ of each primers $(25 \mathrm{~mm})$, and $2 \mu \mathrm{L}(30-50 \mathrm{ng}$ $\mu \mathrm{L}^{-1}$ ) of the isolated genomic DNA as the template. Amplicons of nirK genes were obtained using the primer set nirK1F-nirK5R according to Braker et al., (1998), and nirs genes were targeted with primer pair cd3aF (Michotey et al., 2000) and R3cd (Throback et al., 2004). The modified 'touchdown' protocols for nirK and nirs genes' PCR amplifications were performed. After an initial denaturing step at $95^{\circ} \mathrm{C}$ for $5 \mathrm{~min}, 15$ cycles of $95{ }^{\circ} \mathrm{C}$ for $30 \mathrm{~s}, 55^{\circ} \mathrm{C}$ for $30 \mathrm{~s}$, and $72^{\circ} \mathrm{C}$ for $1 \mathrm{~min}$ were carried out, with a $0.5^{\circ}$ $\mathrm{C}$ step down in annealing temperature of each cycle. This was followed by 20 cycles of $95^{\circ} \mathrm{C}$ for $30 \mathrm{~s}, 48^{\circ} \mathrm{C}$ for $30 \mathrm{~s}$, and $72{ }^{\circ} \mathrm{C}$ for $1 \mathrm{~min}$ and a final extension at $72{ }^{\circ} \mathrm{C}$ for 7 min. Primer sets Scnir372F-Scnir845R developed by Lam et al., (2009) were used to detect Scalindua-nirS genes, and the primer set AnnirS379F-AnnirS821R reported by Li et al., (2011) was also used to detect other anammox bacterial nirS gene by the same PCR protocols showed in previous studies (Lam et al., 2009; Li et al., 2011). The PCR products were checked by electrophoresis on $1 \%$ agarose gels and subsequent staining with $0.5 \mathrm{mg} \mathrm{ml}^{-1}$ gel red. All amplicons for each of the targeted genes showed a single band on the gel except no PCR products could be obtained using the primer set AnnirS379F-AnnirS821R.

\section{Sequencing and phylogenetic analysis}

Amplicons resulting from PCR performed in triplicate for each site were captured (pMD18-T; Takara, Japan), and the resulting clone libraries were prepared for insert sequencing. DNA sequences were determined (ABI Prism 3730 DNA analyzer; Applied Sciences, Foster City, CA, USA) and translated using MEGA 4.0 software (Tamura et al., 2007), and the resulting protein sequences were aligned using CLUSTALW (Thompson et al., 1994). These alignments and the MEGA 4.0 software (neighborjoining algorithm with 1000 times bootstrap resampling) were used to construct phylogenetic trees. Operational taxonomic units (OTUs) were identified using a cutoff of $5 \%$ difference in compared protein sequences, and the DOTUR program was employed to compare the diversity of nirK, nirS, and Scalindua-nirS gene sequences for each sampling site (Schloss \& Handelsman 2005). Correlation analysis between diversity and environmental variables was conducted using Microsoft Excel.

\section{Quantitative analysis of nirK, nirS, and Scalindua-nirS genes}

The abundance of nirK, nirS, and Scalindua-nirs genes in sediment samples was quantified in triplicate using an ABI 7000 Sequence Detection System and Power SYBR Green PCR Master Mix (Applied Biosystems, Foster City, CA, USA). The real-time fluorescent PCR (qPCR) protocols for nirK, nirS, and Scalindua-nirS genes used were the same ones as above for endpoint PCR with exception of the following: (i) the initial denaturing step was at $95^{\circ} \mathrm{C}$ for $10 \mathrm{~min}$; (ii) there was no final extension; (iii) the total number of cycles was 48. A 10 -fold serial dilution $\left(1.02 \times 10^{2}-1.02 \times 10^{8}\right)$ of pMD18 T-plasmids (Takara, Japan) carrying nirK, nirS, and Scalindua-nirS gene insert fragments selected from our clone libraries was used as standards. qPCR amplification efficiencies were 0.94-0.96, 0.95-0.97, and 0.93-0.95 for nirK, nirS, and Scalinduanir $S$, respectively; the correlation coefficients $\left(R^{2}\right)$ of the standard curves were $>0.99$.

\section{Nucleic acid sequence accession numbers}

The GenBank accession numbers for the nirK, nirS, and Scalindua-nirs gene sequences reported here are GQ443760-GQ443888，GQ443889-GQ444002, and GQ444003-GQ444135, respectively.

\section{RESULTS AND DISCUSSION}

\section{Phylogenetic analysis of nirK and nirS genes}

A total of $129 \operatorname{nirK}$ gene sequences obtained from the clone libraries were grouped into three clusters in the phylogenetic tree (Fig. 2). Cluster I, containing $44.4 \%$ of all nirK sequences from station CF5, 5.7\% from station 407, and $4.3 \%$ from station 401 , is affiliated with Alphaproteobacteria, including Rhizobium sp. (82.6\% protein sequence identity), Sinorhizobium sp. (81.8\% protein sequence identity), Ochrobactrum sp. ( $80.5 \%$ protein sequence identity), and Paracoccus sp. (76.7\% protein sequence identity. Sequences in cluster II are closely related to those from Gammaproteobacteria (Pseudomonas sp. $85 \%$ protein sequence identity), representing a minor group with only $30.4 \%$ of the sequences from station $401,17.1 \%$ from station 525, and $2.8 \%$ from station 407 (Fig. 2). Cluster III represents the majority of sequences, containing $65.2 \%$, $91.4 \%, 82.8 \%$, and $55.5 \%$ of the nirK sequences recovered from stations $401,407,515$, and CF5, respectively. Within cluster III, sequences in two subclusters are more closely related to those found in Pacific Northwestern sediments (Jayakumar et al., 2004; Lam et al., 2009) and the corresponding protein sequence identities ranged from $88.0 \%$ to $97.3 \%$. The third subcluster, including only a few clones from stations CF5 and 401, may be considered novel because no sequence-similar to nirK sequences could be retrieved from the sequence databases (Fig. 2) and share less than $30 \%$ identity to amino acid sequence of KSU-1.

The 114 identified nirS gene sequences were clustered in eight phylogenetic groups (Fig. 3). Sequences in cluster I (with two subclusters) are affiliated with Pseudomonas and clones retrieved from Arabian seawater column and marine 
sediment (Dang et al., 2009), and the relative sequence proportions are $21.4 \%, 24.0 \%, 6.9 \%$, and $9.4 \%$ of those obtained from stations 401, 407, 525, and CF5, respectively. Sequences in clusters II and IV are affiliated with the clones found in Jiaozhou Bay, Changjiang Estuary, and California coastal sediments, while those in cluster III containing nine sequences from station 407 are affiliated with the clones found in Hai River sediments and Psendomonas sp. Sequences in cluster $\mathrm{V}$ affiliated with uncultured bacteria of soil, sediment-water interface, Baltic Sea sediment, even the clones obtained from activated sludge, represent $<10 \%$ of the clone libraries obtained from stations 401, 407, and CF5. Cluster VI, including 71.4\%, 32.0\%, 37.9\%, and $28.2 \%$ of the sequences obtained from stations 401,407 , 525 , and CF5, respectively, is the most common nirS gene sequences from South China Sea (SCS) subseafloor sediments, and sequences in this cluster are affiliated with the Betaproteobacteria (Alcaligenes faecalis, Dechloromonas sp.) and uncultured bacteria from activated sludge. Sequences in clusters VII (two sequences from station 525 and one sequence from station CF5) are related to the clones from sediments of estuary, Huntigton Beach, and water column

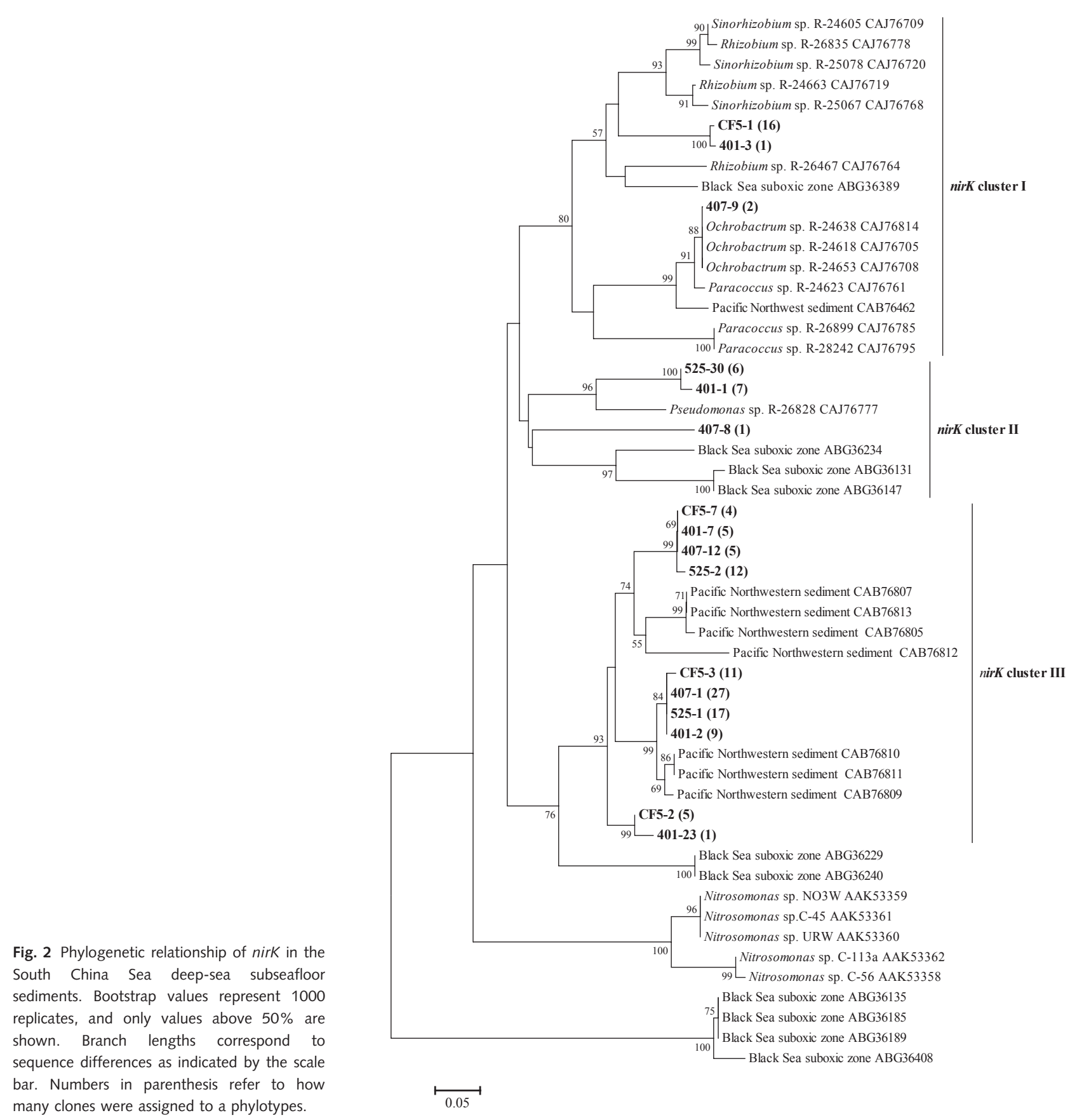




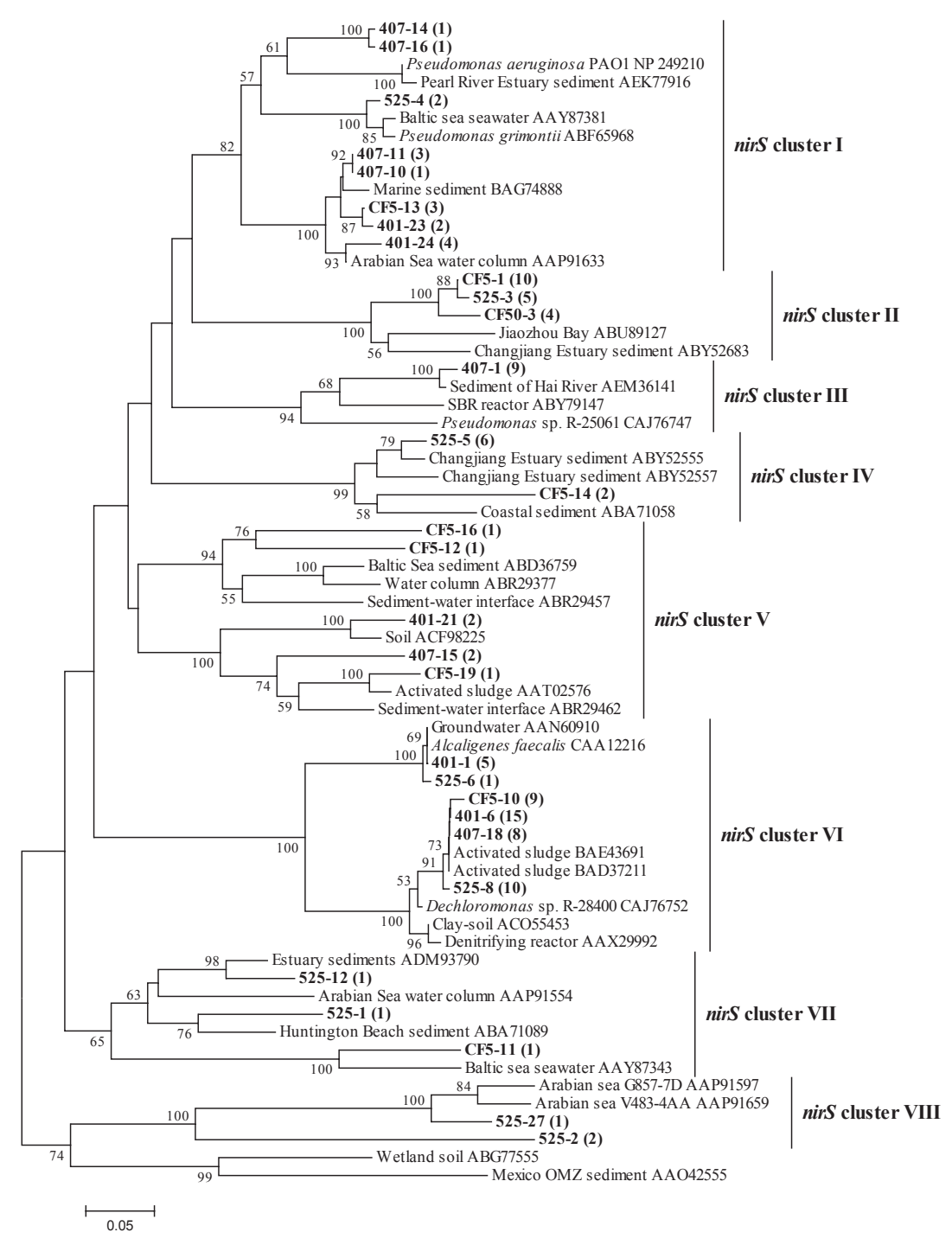

Fig. 3 Phylogenetic relationships of nirS in the South China Sea deep-sea subseafloor sediments. Bootstrap values represent 1000 replicates, and only values above $50 \%$ are shown. Branch lengths correspond to sequence differences as indicated by the scale bar. Numbers in parenthesis refer to how many clones were assigned to a phylotypes. of Arabian Sea and Baltic Sea. Interestingly, three nirS sequences from station 525 appear to form a novel group, cluster VIII, which is distinctively different from deposited and known nirS gene sequences $(<58.1 \%$ protein sequence identity), but share $60.2-63.4 \%$ and $59.0-60.9 \%$ protein sequence identities with Scalindua-nirS sequences detected in the Peruvian OMZ and identified in the genome of anammox bacterium Candidatus 'Kuenenia stuttgartiensis', respectively.

Comparing the diversity of nirS-and nirK-type denitrifiers, three major groups of nirK-type nitrite reducers were detected, including Alphaproteobacteria, Gammaproteobacteria, and uncultured bacteria recovered from Pacific Northwestern sediments, while nirS-type nitrite reducers not only affiliate with known denitrifying Betaproteobacteria (Alcaligenes faecalis and Dechloromonas sp.) and Gammaproteobacteria (Pseudomonas aeruginosa and Psendomonas grimontii), but also with uncultured bacterial nirs clones retrieved from seawater column, coastal and estuary sediments, soils, activated sludge, and SRB reactors. Thus, it appears that the nirS-type nitrite-reducing bacteria are more abundant than nirK-encoding bacteria in deepsea subseafloor sediments. On the other hand, it has been suggested that the diversity of nitrite reducers at a given location may be high during the initial stage of nitrite removal (high ratio of nitrate/nitrite), but lower in later stages of the process when most of the available nitrate/ nitrite is exhausted (Jayakumar et al., 2009). If this holds true for deep-ocean subseafloor sediments, more nitrite reducers are expected at site 401 , where the nitrate/nitrite ratio was the highest among all sites in this study (Fig. 1). To our surprise, this general pattern was applicable only to nirK gene abundance and diversity, not to nirs. Our results are in agreement with those by Oakley et al., (2007) for the Black Sea suboxic zone, showing a clear difference between nirK- and nirS-encoding nitrite reducers due to physical and chemical differences in these sampling stations. 


\section{Phylogenetic analysis of Scalindua-nirS gene}

A previous study (Oakley et al., 2007) focused on anammox bacterial nirS gene abundance and distribution in the Black Sea suboxic zone, but failed to retrieve any due to mismatches with the employed primers. Only recently, two primer sets have been developed for targeting nirs genes in anammox bacteria (Lam et al., 2009; Li et al., 2011). Using the two new primer sets, anammox bacterial related nirs gene sequences were only obtained using the primer set Scnir372F-Scnir845R, which is consistent with our previous results ( $\mathrm{Li}$ et al., 2011). A total of 133 clones in the Scalindua-nirS group with high protein sequence identities (80.0-91.7\%) to Scalindua-nirS gene sequences retrieved from the water column of Peruvian OMZ (Lam et al., 2009) and sediments of the SCS and Mai Po mangrove wetland ( $\mathrm{Li}$ et al., 2011). These retrieved sequences also showed high protein sequence identity (60.0-61.4\%) with the nirs gene in the genome of anammox bacterium Candidatus Kuenenia stuttgartiensis', but lower identity
$(<58 \%)$ with nirS genes from known denitrifiers (Fig. 4). In addition, all sequences grouped phylogenetically in a distinct clade separate from the group of nirs gene from classical denitrifiers. The clade contains five clusters, of which Scalindua-nirs cluster I to III includes $70.9 \%$, $84.3 \%, 68.6 \%$, and $77.1 \%$ of the sequences obtained from stations 401, 407, 515, and CF5, respectively. While sequences in cluster $\mathrm{V}$ were closely related to the sequences of the SCS surface sediment, sequences in both clusters IV and $\mathrm{V}$ formed unique groups clearly different from those found in the Peruvian OMZ, thereby indicating presence of a SCS site-specific sequence cluster (Fig. 4). To our knowledge, this is the first report of Scalindua-nirS gene sequences from the deep-ocean subseafloor biosphere, which extends our knowledge about anammox and denitrifying processes in natural ecosystem. In our previous study, a variety of Scalindua-like anammox bacteria was detected in these samples, including five different 16S rRNA and hydrazine oxidoreductase $(b z o)$ gene subclusters (Hong et al., 2011). Our current results in this study are
Fig. 4 Phylogenetic relationships of Scalindua-nirs in deep-ocean subseafloor sediments of the South China Sea. Bootstrap values represent 1000 replicates, and only values above $50 \%$ are shown. Branch lengths correspond to sequence differences as indicated by the scale bar. Numbers in parenthesis refer to how many clones were assigned to a phylotypes.

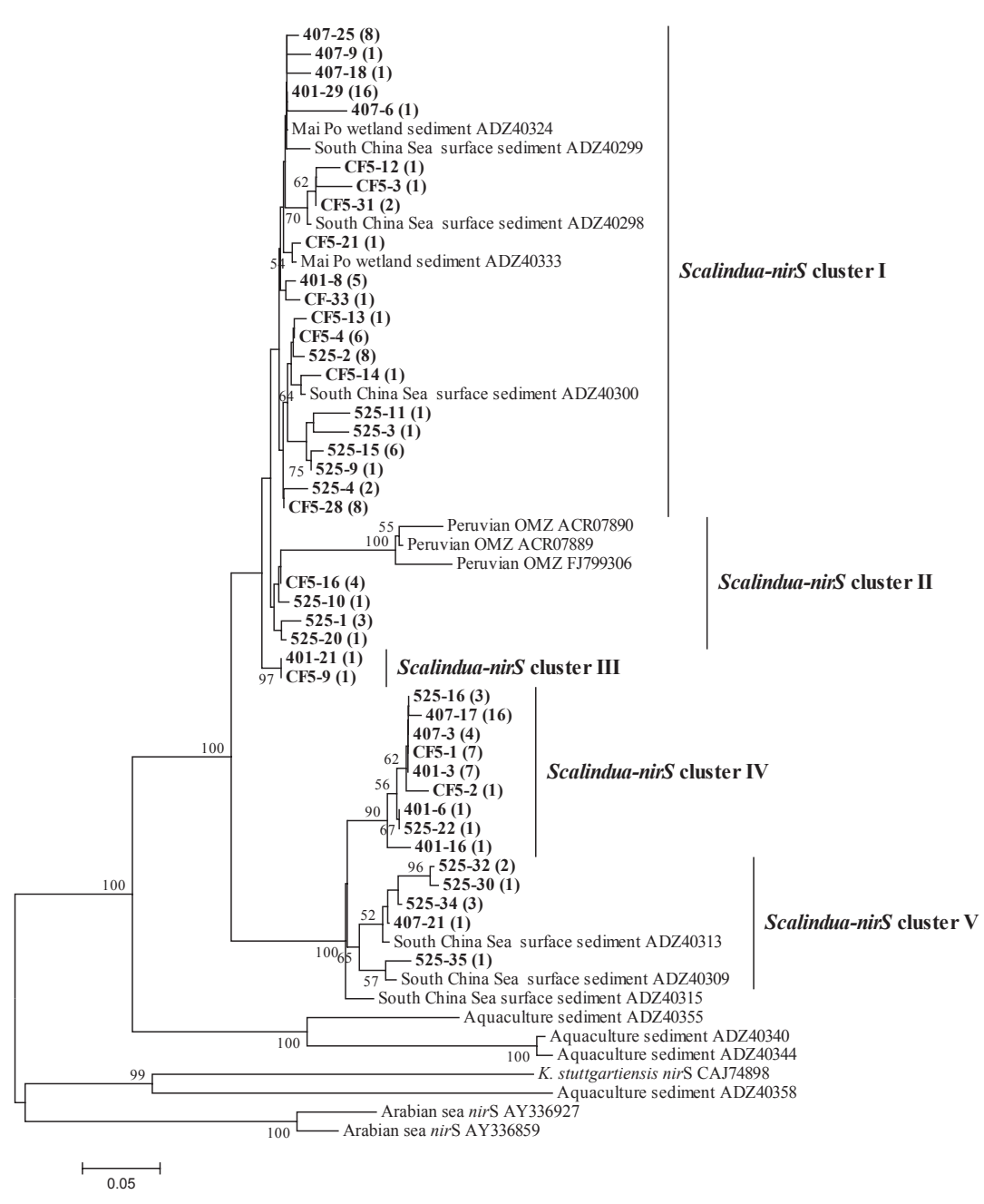


consistent with the previous ones, further confirm the Scalindua-nirS as an effective functional biomarker for detection and analysis of marine anammox bacteria. Although the five different clusters of Scalindua-nirS gene could not be perfectly matched with those of anammox bacteria $16 \mathrm{~S}$ rRNA and hzo genes as shown in our previous study (Hong et al., 2011), Scalindua-nirs gene provides an additional biomarker and more comprehensive analysis of the phylogenetic diversity and composition of anammox bacteria in the marine ecosystem.

\section{Abundance of nirK, nirS, and Scalindua-nirS genes}

The nirK gene abundance in the four sampling sites ranged from $1.74( \pm 0.73) \times 10^{5}$ to $1.30( \pm 0.01) \times 10^{3}$ copies $/ g$ (dry mass sediments), for which site 525 had the lowest. The nirS gene abundance varied from $2.06( \pm 0.26) \times 10^{6}$ to $4.29( \pm 0.81) \times 10^{5}$ copies $/ g$, and Scalindua-nirS ranged from $2.34( \pm 0.24) \times 10^{5}$ to $2.06( \pm 0.21) \times 10^{5}$ copies $/ g$ (Table 1). Interestingly, both nirS and Scalindua-nirS genes showed similar abundance distribution patterns and the highest abundance of nirS and Scalindua-nirs genes was detected at station 525 , followed by station CF5, with the lowest abundance at station 407. The nirK gene followed a reverse distribution pattern, in which site 407 had the highest abundance and station 525 had the lowest (Table 1). However, comparing with our previous results of anammox bacteria described by $16 \mathrm{~S}$ rRNA and hzo genes at these stations, abundance of Scalindua-nirS in this study was much higher and relatively even, possibly due to the low qPCR efficiency with a longer hzo gene amplicons (>1000 bp) (Hong et al., 2011); thus, new PCR primers for the qPCR of hzo genes are needed in the future.

\section{Distribution of nirK, nirS, and Scalindua-nirS genes and their relationships with environmental factors}

The geographical distribution of nirK, nirS, and Scalindua-nirS genes in subsurface sediments of the SCS was investigated and compared with other marine ecosystems using the Unifrac package (Figs S1-S3) (Lozupone et al., 2006). Jackknife environmental clustering and principal coordinate analysis (PCoA) identified that nirS and Scalindua-nirS genes share a similar geographic distribution pattern and similar structures of nirS- and Scalindua-nirSencoding microbial communities among the four stations, but not for nirK genes. The nirS gene sequences recovered from the SCS subseafloor were clearly different from those retrieved from Pacific Northwestern sediments (Braker et al., 2001), the Black Sea suboxic zone (Oakley et al., 2007), the Baltic Sea (Hannig et al., 2006), the Arabian Sea (Jayakumar et al., 2004), and the Peruvian OMZ (Lam et al., 2009), and Scalindua-nirS gene sequences of this study were different from Mai Po wetland, marine aquaculture zone (Li et al., 2011), and the Peruvian OMZ (Lam et al., 2009), while the nirK gene distribution reflected similar community structures as found in the Pacific Northwestern sediments (Braker et al., 2001), suggesting that the SCS subsurface sediments serve as a site-specific niche for nirS and Scalindua-nirS communities (Figs S1-S3). The correlation analysis was further used to identify the relationships among different physiochemical parameters with the diversity and abundance of the three targeted genes (Table 2). Results indicated that diversity of nirK gene was positively correlated with the seawater depth of the sampling stations, while the nirS and Scalindua-nirS genes were negatively correlated, especially for the nirS gene, showing a very significant negative relationship with seawater depth. However, when comparing the relationship of abundance of the three genes with environmental factors, nirS and Scalindua-nirS genes were positively correlated with the ratio of $\mathrm{NH}_{4}{ }^{+} /\left(\mathrm{NO}_{2}{ }^{-}+\mathrm{NO}_{3}{ }^{-}\right)$, while the nirK gene abundance was very negatively correlated with the ratio of $\mathrm{NH}_{4}{ }^{+} /\left(\mathrm{NO}_{2}{ }^{-}+\mathrm{NO}_{3}{ }^{-}\right)$. These results further indicated that nirS and Scalindua-nirS genes were similarly distributed with similar responses to the environmental factors in deep-ocean subsurface sediments, which differed from that of nirK. Furthermore, the significant correlation between the Scalindua-nirS abundance and seawater depth also indicated that the seawater depth might strongly affect

Table 1 Diversity characteristics and abundance of nirK, nirS, and Scalindua-nirS genes in subseafloor sediments of the South China Sea

\begin{tabular}{|c|c|c|c|c|c|c|c|c|}
\hline Groups & Sites & Clone numbers & OTUs & Shannon & Simpson & Chaol & Coverage & Abundance $\left(\times 10^{4} \mathrm{~g}^{-1}\right)$ \\
\hline \multirow[t]{4}{*}{ nirk } & E401 & 23 & 5 & 1.33 & 0.26 & 6 & 0.91 & $5.03 \pm 0.58$ \\
\hline & E407 & 35 & 5 & 1.07 & 0.27 & 5 & 0.97 & $17.34 \pm 7.33$ \\
\hline & E525 & 35 & 3 & 1.02 & 0.36 & 3 & 1 & $0.13 \pm 0.01$ \\
\hline & CF5 & 36 & 4 & 1.24 & 0.30 & 4 & 1 & $1.153 \pm 0.56$ \\
\hline \multirow[t]{4}{*}{ nirs } & E401 & 28 & 5 & 1.30 & 0.33 & 5 & 1 & $144.21 \pm 29.43$ \\
\hline & E407 & 25 & 7 & 1.58 & 0.23 & 8.5 & 0.88 & $42.90 \pm 8.05$ \\
\hline & E525 & 29 & 11 & 2.17 & 0.11 & 12.5 & 0.86 & $206.42 \pm 25.66$ \\
\hline & CF5 & 32 & 11 & 2.07 & 0.13 & 14.3 & 0.84 & $145.20 \pm 24.12$ \\
\hline \multirow[t]{4}{*}{ Scalindua-nirs } & E401 & 31 & 4 & 1.11 & 0.36 & 4 & 0.97 & $20.64 \pm 2.14$ \\
\hline & E407 & 32 & 6 & 1.29 & 0.33 & 9 & 0.91 & $21.25 \pm 3.48$ \\
\hline & E525 & 35 & 9 & 2.01 & 0.12 & 12 & 0.91 & $23.41 \pm 2.42$ \\
\hline & CF5 & 35 & 6 & 1.49 & 0.24 & 7 & 0.94 & $23.10 \pm 2.50$ \\
\hline
\end{tabular}


Table 2 Statistical analysis of physiochemical parameters with diversity and abundance of nirK, nirS, and Scalindua-nirS genes

\begin{tabular}{|c|c|c|c|c|c|c|}
\hline Groups & Environmental factors & OTUs & Shannon & Simpson & Chaol & Abundance \\
\hline \multirow[t]{7}{*}{ nirk } & Seawater depth & 0.76 & 0.65 & -0.75 & 0.93 & 0.29 \\
\hline & Sediment depth & -0.44 & 0.43 & 0.28 & -0.36 & -0.33 \\
\hline & $\mathrm{NH}_{4}^{+}$ & 0.29 & 0.76 & -0.35 & 0.59 & -0.33 \\
\hline & $\mathrm{NO}_{x}$ & 0.51 & 0.71 & -0.53 & 0.76 & -0.06 \\
\hline & $\mathrm{NO}_{2}^{-}$ & 0.18 & -0.05 & -0.08 & 0.37 & 0.15 \\
\hline & $\mathrm{NH}_{4}^{+} / \mathrm{NO}_{2}^{\dagger}$ & 0.24 & 0.76 & -0.30 & 0.54 & -0.39 \\
\hline & $\mathrm{NH}_{4}^{+} / \mathrm{NO}_{x}^{\dagger}$ & -0.77 & 0.14 & 0.67 & -0.56 & $-0.99 *$ \\
\hline \multirow[t]{7}{*}{ nirs } & Seawater depth & $-0.95^{*}$ & $-0.95^{*}$ & $0.98^{*}$ & $-0.95^{*}$ & -0.25 \\
\hline & Sediment depth & 0.60 & 0.54 & -0.46 & 0.63 & 0.57 \\
\hline & $\mathrm{NH}_{4}^{+}$ & -0.59 & -0.59 & 0.69 & -0.65 & 0.35 \\
\hline & $\mathrm{NO}_{x}$ & -0.79 & -0.78 & 0.86 & -0.83 & 0.10 \\
\hline & $\mathrm{NO}_{2}^{-}$ & -0.63 & -0.55 & 0.59 & -0.77 & 0.11 \\
\hline & $\mathrm{NH}_{4}^{+} / \mathrm{NO}_{2}^{\dagger}$ & -0.53 & -0.53 & 0.64 & -0.60 & 0.40 \\
\hline & $\mathrm{NH}_{4}^{+} / \mathrm{NO}_{x}^{\dagger}$ & 0.60 & 0.60 & -0.49 & 0.51 & $0.96 *$ \\
\hline \multirow[t]{7}{*}{ Scalindua-nirs } & Seawater depth & -0.81 & -0.79 & 0.81 & -0.78 & $-0.92 *$ \\
\hline & Sediment depth & 0.03 & 0.23 & -0.36 & -0.20 & 0.60 \\
\hline & $\mathrm{NH}_{4}^{+}$ & -0.59 & -0.43 & 0.39 & -0.72 & -0.51 \\
\hline & $\mathrm{NO}_{x}$ & -0.69 & -0.60 & 0.59 & -0.75 & -0.54 \\
\hline & $\mathrm{NO}_{2}^{-}$ & -0.08 & -0.11 & 0.19 & -0.05 & -0.54 \\
\hline & $\mathrm{NH}_{4}^{+} / \mathrm{NO}_{2}^{\dagger}$ & -0.55 & -0.39 & 0.34 & -0.70 & -0.45 \\
\hline & $\mathrm{NH}_{4}^{+} / \mathrm{NO}_{x}^{\dagger}$ & 0.39 & 0.60 & -0.69 & 0.12 & 0.68 \\
\hline
\end{tabular}

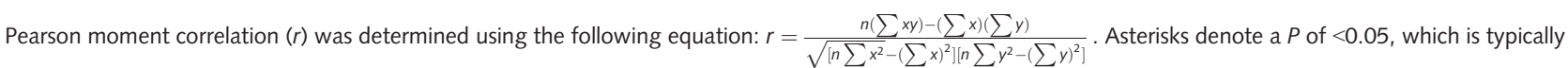
regarded as significant, as determined by Excel function TDIST from the $t$ value given by the following equation: $t=r \times \sqrt{\frac{n-2}{(1-r)^{2}}}$. The number of samples is given by $n$. $\uparrow$ Ratios of ammonium to oxidized inorganic species (nitrite or nitrate plus nitrite).

the distribution of anammox bacteria, which has also been reported in other studies (Engstrom et al., 2009; Glud et al., 2009; Trimmer \& Nicholls 2009).

By combining these results, it can be concluded that the distribution of nirS- and Scalindua-nirS-encoding communities is likely controlled by the same set of environmental factors or that they might respond similarly to the environmental gradients in the subsurface ecosystem of the SCS (Dang et al., 2010). Because nitrite reduction is dependent on the presence of active nitrite reductases (Zumft 1997), it is reasonable to propose that a similar distribution pattern within bacteria containing nirS genes, different from that of nir $K$-type nitrite reducers, is due to the different types of nitrite reductase-encoding genes in these microbes and the different regulation of metabolic mechanism in the context of their nitrite reduction. Similar gene distribution patterns of denitrifier-nirS and Scalindua-nirS were also reported in the Peruvian OMZ (Lam et al., 2009). Furthermore, the report that nirS communities responded differently to environmental gradients than nirK communities in diverse ecosystems (Jones \& Hallin 2010) supports our finding in that coexisting populations of nirS-type nitrite reducers and anammox bacteria follow similar or identical community assembly rules imposed by their surrounding environment, which is different from nirK nitrite reducer communities.

In conclusion, the nirS-encoding nitrite-reducing bacteria showed much higher diversity and abundance than the nirK-encoding nitrite reducers in subseafloor sediments of the SCS, indicating that nirS-encoding communities may play a more important role in contributing to the overall nitrogen removal in deep-sea subsurface sediments. The nirS-type nitrite reducers and Scalindua anammox bacteria share similar distributions, different from that of nirK-type nitrite reducers, proposing different responses of these three groups of micro-organisms to environmental gradients in the deep-sea subseafloor sediments.

\section{ACKNOWLEDGMENTS}

This research was supported by a PhD studentship (ML) and Environmental and Conservation Fund (No. 15/2011) (J-DG), National Natural Science Foundation of China (41076095, 30800032) (Y-GH), and South China Sea Open Cruise by R/V Shiyan 3, South China Sea Institute of Oceanology, CAS. We thank two anonymous reviewers for their valuable comments and suggestions to improve this manuscript from an earlier draft and Jessie Lai for general laboratory support for conducting this study at The University of Hong Kong. All authors of this manuscript have no conflict of interest to declare.

\section{REFERENCES}

Braker G, Fesefeldt A, Witzel KP (1998) Development of PCR primer systems for amplification of nitrite reductase genes (nir K and nirs) to detect denitrifying bacteria in 
environmental samples. Applied and Environment Microbiology 64, 3769-3775.

Braker G, Ayala-Del-Rio HL, Devol AH, Fesefeldt A, Tiedje JM (2001) Community structure of denitrifiers, bacteria, and archaea along redox gradients in Pacific Northwest marine sediments by terminal restriction fragment length polymorphism analysis of amplified nitrite reductase (nirS) and 16S rRNA genes. Applied and Environment Microbiology 67, 1893-1901.

Cao Y, Green PG, Holden PA (2008) Microbial community composition and denitrifying enzyme activities in salt marsh sediments. Applied and Environment Microbiology 74, 75857595 .

Cao HL, Hong YG, , Li M, Gu J-D (2012) Lower abundance of ammonia-oxidizing archaea than ammonia-oxidizing bacteria detected in the subsurface sediments of the Northern South China Sea. Geomicrobiology Journal 29, 332-339.

Dang H, Wang C, Li J, Li T, Tian F, Jin W, Ding Y, Zhang Z (2009) Diversity and distribution of sediment nirS-encoding bacterial assemblages in response to environmental gradients in the eutrophied Jiaozhou Bay, China. Microbial Ecology 58, 161-169.

Dang H, Chen R, Wang L, Guo L, Chen P, Tang Z, Tian F, Li S, Klotz MG (2010) Environmental factors shape sediment anammox bacterial communities in hypernutrified Jiaozhou Bay, China. Applied and Environment Microbiology 76, 7036-7047.

Engstrom P, Penton CR, Devol AH (2009) Anaerobic ammonium oxidation in deep-sea sediments off the Washington margin. Limnology and Oceanography 54, 1643-1652.

Francis CA, Beman JM, Kuypers MM (2007) New processes and players in the nitrogen cycle: the microbial ecology of anaerobic and archaeal ammonia oxidation. ISME Journal 1, 19-27.

Glud RN, Thamdrup B, Stahl H, Wenzhoefer F, Glud A, Nomaki H, Oguri K, Revsbech NP, Kitazato H (2009) Nitrogen cycling in a deep ocean margin sediment (Sagami Bay, Japan).

Limnology and Oceanography 54, 723-734.

Hannig M, Braker G, Dippner J, Jurgens K (2006) Linking denitrifier community structure and prevalent biogeochemical parameters in the pelagial of the central Baltic Proper (Baltic Sea). FEMS Microbiology Ecology 57, 260-271.

Hong YG, Li M, Cao H, Gu J-D (2011) Residence of habitatspecific anammox bacteria in the deep-sea subsurface sediments of the South china sea: analyses of marker gene abundance with physical chemical parameters. Microbial Ecology 62, 36-47.

Jayakumar DA, Francis CA, Naqvi SWA, Ward BB (2004) Diversity of nitrite reductase genes (nirS) in the denitrifying water column of the coastal Arabian Sea. Aquatic Microbial Ecology 34, 69-78.

Jayakumar A, O'mullan GD, Naqvi SW, Ward BB (2009) Denitrifying bacterial community composition changes associated with stages of denitrification in oxygen minimum zones. Microbial Ecology 58, 350-362.

Jetten MS, Niftrik LV, Strous M, Kartal B, Keltjens JT, Op Den Camp HJ (2009) Biochemistry and molecular biology of anammox bacteria. Critical Reviews in Biochemistry and Molecular Biology 44, 65-84.

Jones CM, Hallin S (2010) Ecological and evolutionary factors underlying global and local assembly of denitrifier communities. ISME Journal 4, 633-641.

Kartal B, Kuypers MM, Lavik G, Schalk J, Op Den Camp HJ, Jetten MS, Strous M (2007) Anammox bacteria disguised as denitrifiers: nitrate reduction to dinitrogen gas via nitrite and ammonium. Environmental Microbiology 9, 635-642.
Klotz MG, Stein LY (2010) Genomics of ammonia-oxidizing bacteria and insights to their evolution. In Nitrification (eds Ward BB, Arp DJ, Klotz MG). ASM Press, Washingtong, DC, pp. 57-93.

Lam P, Lavik G, Jensen MM, Van De Vossenberg J, Schmid M, Woebken D, Gutierrez D, Amann R, Jetten MS, Kuypers MM (2009) Revising the nitrogen cycle in the Peruvian oxygen minimum zone. Proceedings of the National Academy of Sciences USA 106, 4752-4757.

Li M, Ford T, Li X, Gu J-D (2011) Cytochrome $c d_{1}$-containing nitrite reductase encoding gene $n i r S$ as a new functional biomarker for detection of anaerobic ammonium oxidizing (Anammox) bacteria. Environmental Science and Technology 45, 3547-3553.

Lozupone C, Hamady M, Knight R (2006) UniFrac-an online tool for comparing microbial community diversity in a phylogenetic context. BMC Bioinformatics 7, 371 .

Michotey V, Mejean V, Bonin P (2000) Comparison of methods for quantification of cytochrome $c d_{1}$-denitrifying bacteria in environmental marine samples. Applied and Environment Microbiology 66, 1564-1571.

Oakley BB, Francis CA, Roberts KJ, Fuchsman CA, Srinivasan S, Staley JT (2007) Analysis of nitrite reductase (nirK and nirS) genes and cultivation reveal depauperate community of denitrifying bacteria in the Black Sea suboxic zone. Environmental Microbiology 9, 118-130.

Santoro AE, Boehm AB, Francis CA (2006) Denitrifier community composition along a nitrate and salinity gradient in a coastal aquifer. Applied and Environment Microbiology 72, 2102-2109.

Schloss PD, Handelsman J (2005) Introducing DOTUR, a computer program for defining operational taxonomic units and estimating species richness. Applied and Environment Microbiology 71, 1501-1506.

Schmidt I, Sliekers O, Schmid M, Bock E, Fuerst J, Kuenen JG, Jetten MS, Strous M (2003) New concepts of microbial treatment processes for the nitrogen removal in wastewater. FEMS Microbiology Reviews 27, 481-492.

Smith CJ, Nedwell DB, Dong LF, Osborn AM (2007) Diversity and abundance of nitrate reductase genes (nar $\mathrm{G}$ and napA), nitrite reductase genes ( $n i r \mathrm{~S}$ and $n r f \mathrm{~A}$ ), and their transcripts in estuarine sediments. Applied and Environment Microbiology 73, 3612-3622.

Strous M, Fuerst JA, Kramer EH, Logemann S, Muyzer G, Van De Pas-Schoonen KT, Webb R, Kuenen JG, Jetten MS (1999) Missing lithotroph identified as new planctomycete. Nature 400, 446-449.

Strous M, Pelletier E, Mangenot S, Rattei T, Lehner A, Taylor MW, Horn M, Daims H, Bartol-Mavel D, Wincker P, Barbe V, Fonknechten N, Vallenet D, Segurens B, Schenowitz-Truong C, Medigue C, Collingro A, Snel B, Dutilh BE, Op Den Camp HJ, Van Der Drift C, Cirpus I, Van De Pas-Schoonen KT, Harhangi HR, Van Niftrik L, Schmid M, Keltjens J, Van De Vossenberg J, Kartal B, Meier H, Frishman D, Huynen MA, Mewes HW, Weissenbach J, Jetten MS, Wagner M, Le Paslier D (2006) Deciphering the evolution and metabolism of an anammox bacterium from a community genome. Nature $\mathbf{4 4 0}$, 790-794.

Tamegai H, Aoki R, Arakawa S, Kato C (2007) Molecular analysis of the nitrogen cycle in deep-sea microorganisms from the Nankai Trough: genes for nitrification and denitrification from deep-sea environmental DNA. Extremophiles 11, 269-275. 
Tamura K, Dudley J, Nei M, Kumar S (2007) MEGA4: molecular Evolutionary Genetics Analysis (MEGA) software version 4.0. Molecular Biology and Evolution 24, 1596-1599.

Thompson JD, Higgins DG, Gibson TJ (1994) CLUSTAL W: improving the sensitivity of progressive multiple sequence alignment through sequence weighting, position-specific gap penalties and weight matrix choice. Nucleic Acids Research 22, $4673-4680$.

Throback IN, Enwall K, Jarvis A, Hallin S (2004) Reassessing PCR primers targeting nirS, nirK and nos Z genes for community surveys of denitrifying bacteria with DGGE. FEMS Microbiology Ecology 49, 401-417.

Trimmer M, Nicholls JC (2009) Production of nitrogen gas via anammox and denitrification in intact sediment cores along a continental shelf to slope transect in the North Atlantic.

Limnology and Oceanography 54, 577-589.

Zumft WG (1997) Cell biology and molecular basis of denitrification. Microbiology and Molecular Biology Reviews 61, $533-616$.

\section{SUPPORTING INFORMATION}

Additional Supporting Information may be found in the online version of this article:

Fig. S1 Jackknife Environmental Clusters (a) and PCoA (b) for the South China Sea deep-ocean subseafloor sediments nirK protein sequences and representative data from Pacific Northwestern sediments, Black Sea suboxic zone and California coastal sediments.

Fig. S2 Jackknife Environmental Clusters (a) and PCoA (b) for the South China Sea deep-ocean subseafloor sediments nirS protein sequences and representative data from Pacific Northwestern sediments, Black Sea suboxic zone, Peruvian $\mathrm{OMZ}$, Arabian $\mathrm{OMZ}$, and Baltic Sea.

Fig. S3 Jackknife Environmental Clusters (a) and PCoA (b) for the South China Sea deep-ocean subseafloor sediments Scalindua-nirS protein sequences and representative data from Peruvian $O M Z$, Marine aquaculture zone, Mai Po Natural Reserve.

\section{ADDENDUM}

Recently, $\mathrm{Hu}$ et al. (2012) reported the function of copper-nitrite reductases (NirK) in anammox bacteria, which allowed for a new perspective on the evolution of nitrite reduction in the anammox process (Front. Microbio. 3:366. doi:10.3389/fmicb.2012.00366).

van de Vossenberg et al. (2012) showed the functional replacement of the likely ancient multi-heme cytochrome c reductase (reverse HAO) by NirK in Jettenia asiatica and KSU-1 (Environ Microbiol. doi:10.1111/j.1462-2920. 2012.02774.x. 